\title{
The Position-Classification Plan. for University Libraries
}

\author{
Mr. Bartolini is librarian, Kansas State \\ Teachers College, Pittsburg.
}

I N THIS article aspects of theory regarding the place of a position-classification plan in university library personnel administration will be discussed. In addition, the more specific advantages and uses of such a plan for university libraries will be summarized.

For the purposes here, a position-classification plan may be defined as a comprehensive, systematic scheme of grouping positions according to certain prescribed criteria, with a code of rules for the establishment, maintenance, and amendment of the system.

\section{Some Concepts of Position-Classification}

At the outset, certain criteria for the classification of positions should be established. Once decided upon, only these criteria should be considered in establishing a position-classification plan. Since the purpose of the plan is to serve as an administrative tool in personnel administration for such matters as fixing pay, establishing minimum qualifications, recruiting, and maintaining an effective working force, the bases for the classification of positions are: (I) the duties and responsibilities of the positions, (2) the qualifications required to fill them, and (3) salaries.

A characteristic of a position-classification plan is that it is flexible. It must be clear that the whole system is a plan, and not merely a system of classes with specifications. Though the plan is established on current duties and responsibilities of present positions, it is a plan for the future because internal flexibility is possible. As changes occur in positions, they are reported to the personnel office or other agency in charge of the plan. Thus, the flexibility discussed does not refer to expandibility, but capacity of the plan to be kept up-to-date. As new duties and responsibilities are assigned, and as old duties and responsibilities are eliminated, necessary changes within the position-classification plan are made.

A popular misconception is that duties must be listed in a certain class of a position-classification plan before those duties and responsibilities can be assigned to individuals holding positions in that class. This is not the case. On the contrary, a basic concept is that an original analysis of position make-up will often indicate the existence of too varied a group of duties and responsibilities in individual positions. The solution to such a situation is left to the administration of a particular organization.

The point is, then, that a position-classification plan is not binding but descriptive. It is a guide easily referred to and as objective as humanly possible. Changes within positions are referred to the organization's personnel officer or other person in charge of maintaining the position-classification plan. 
The relationship between a positionclassification plan and a pay plan is often close. This is because the former, as an administrative tool, is often the basis of the separate pay plan. A position-classification plan and a pay plan are distinct in basis, purpose, and technique. A pay plan must consider cost of living, supply of candidates, budget limitations, local pay scales, and many other factors not relevant to a position-classification plan. Position-classification is based upon the duties and responsibilities of a position.

Classes of positions with class specifications, as they are seen in written form, often appear to the inexperienced eye to be an end in themselves. This is clearly not the case. The position-classification plan is a means of greatly facilitating the accomplishment of many of the objectives of personnel administration. As a technique or tool, it is kept flexible and fit for current use. In part, then, the position-classification plan facilitates the adjustments operating to keep the right person in the right job. For example, as a position is left vacant, a new analysis of the position and comments from its immediate supervisor, brings up the latest information on the work and responsibilities of the position. This information assists in selecting exactly the right person for that position.

\section{Implications of the Position-Classification Plan to University Libraries}

It is probable that university libraries generally have lagged behind public libraries in establishing, developing, and using position-classification plans. For this reason, an attempt is made to indicate advantages of position-classification plans to university librarianship. It behooves university librarians to assume the initiative and establish position-classification plans in their libraries. Such action may do much in indicating that librarians should be considered as teaching staff in personnel administration policies of universities.

Consideration of the relationship between a position-classification plan and recruitment of personnel to fill university positions may throw further light on the subject. Because of the position-classification plan, the recruiting or personnel officer has available to him a detailed analysis of the make-up of the vacant position. He sees the position's organizational relationships not only as brought out by the organizational chart of the library, but a variation of this position's relationship as well, if a job analysis has indicated such a variation. That is, although a certain position has a second position as its immediate higher level, job descriptions may show that the incumbent of a third position actually acts as immediate supervisor to the position we are discussing. The hiring officer will also have typical duties and responsibilities of the position before him in written form. In an ideal class specification, there is a statement of desirable qualifications of the person for that position, based upon the work to be done.

In university libraries it would not matter if the system were not large enough to have a full-time personnel officer. Should the head librarian retain responsibility for the personnel function, as in a smaller system, he would profit nonetheless from a formal position-classification plan for his recruiting activities. He would save time, money, and confusion by using this tool which obviates the repeated attempts to determine duties and qualifications of position and candidate each time a vacancy occurs and a new person needs to be employed.

Another area of personnel administration in a university library facilitated by the existence of a position-classification plan is 
selection of staff. Specifications for each class of position give the duties, responsibilities, and qualification standards for the position.

\section{Promotional Sequence}

Study of an available position-classification plan and of the organizational structure of a university library will yield understanding of relationships of positions and of levels of work. With this knowledge of the relationships of positions, promotional sequence is seen more clearly. Both promotions and transfers are based on the assumption that comparison between the two positions exists. This type of information is obtainable from a positionclassification plan.

Because organized objective information on the library's positions is available in the position-classification plan, intelligent understanding of the activities of library personnel is easy to attain. As a minor, by-product advantage to university library administrators, this would mean less confusion to personnel administration in the event of the loss of an experienced personnel officer. Likewise, the plan offers him an excellent means of presenting data to busy university officials and budget officers.

Another value of a position-classification plan is suggested by L. D. White, who writes:

Confusion in the distribution of authority, overlapping duties, and other sources of poor administration are almost certain to appear in the process of getting at the fact on which an allocation rests. This is one of the subsidiary but important advantages of a classification plan. ${ }^{1}$

A word might be said of the values of position-classification plans in the organiza-

1 White, L. D. Introduction to the Study of Public Administration, rev. ed. New York, Macmillan, r939, p. 335 . tion of the university library. From the first, it is to be remembered that the organizational structure is flexible. Humans change through experience, sickness, aging, and multiple other causes. As a result, executives reconsider organizational structures for this human as well as several impersonal factors.

\section{Plan Affords Clarity}

Certainly the position-classification process does not in itself prescribe changes in organizational structure, flow of work, work responsibilities, and the several other indications of over-all organization. But due to the inventory or analysis of the duties and responsibilities in positions, executives clearly see and understand how objectives of the university library may be attained better through some departmental or library-wide reorganization. The position-classification plan then affords a degree of clarity which its absence may deny the administration.

With his organization seen in a clearer light because of an analysis-based positionclassification scheme, the university librarian is able to plan reorganization he may see necessary. He will want to consider factors which will come to him because of his experience. He would consult with and obtain suggestions from his staff, of course. But the newly instituted position-classification plan based on an analysis of positions may provide the final, determining argument for executing a change contemplated for some time but not made because of the lack of evidence.

Along with an organizational chart, a position-classification plan shows an executive's span of control and provides a check on its reasonable size. Such a study indicates the degree of homogeneity of grouped activities. The plan also provides a check to reveal the number of supervisory levels. 
The study of a position-classification plan, be it made by a member of the staff or by the library's own administrator, adds to his understanding of the delegation of authority and responsibility. Duplications of work, gaps in responsibility, and overlapping authority are seen more easily with the presentation of the organization of a library through a good position-classification plan.

The opinion of one group is that:

Major executives, responsible for administrative organization and organization structure, can with great advantage study carefully the pertinent facts collected by the classification agency in its investigation and surveys. Practical aspects of the situation suggest that classification staffs are in strategic positions to render advice on organizational matters. ${ }^{2}$

Staff morale is considered of serious importance in university libraries because of the demand that the level of work be high. In the public services, for example, staffs with high morale work more efficiently and generally are more able to establish rapport with the public. On this point of morale, it has been observed that salary inequalities are more potent sources of dissatisfaction than the general level of pay. It is in this area that a position-classification plan can assist to make employee-management relations smooth, by providing for equal pay for equal work.

\section{Class Specifications Aid Librarians}

To an individual librarian, especially in a large university library, class specifications may be a map informing him as to where he is now and as to where he may advance. Class specifications of a positionclassification plan provide the ambitious employee with some information on how he may prepare himself for a higher-grade

2 Civil Service Assembly. Position-Classification in the Public Service. A report by the Committee on Position-Classification and Pay Plans. Chicago, Civil Service Assembly, 1941, p. 78 . position which he finds described for him. $\mathrm{He}$ needs more than general knowledge for his self-improvement program.

Two necessary factors are basic for high morale. They are: (I) that the job be clearly defined in writing; (2) that the relationship of this job to other positions and activities (to the whole university library in other words) also be made clear. A position-classification plan enables these two suggested conditions to be present.

From time to time, a library attempts employee-training programs in order to obtain people who can intelligently perform the tasks of a particular library. Certainly librarians cannot be prepared intelligently in a library unless the nature, duties, and responsibilities of the job for which they are to be trained are definitely described. Indecision is likely to exist with in-service training programs not backed by information from the position-classification plan. So, because a position-classification scheme does lay down the nature, duties, and responsibilities of positions, it is of great aid in a library's in-service training program.

\section{Foundation for Pay Plan}

Since a position-classification plan groups positions according to similarity of work and responsibilities, it is a sound foundation for an equitable pay plan. It is said that "experience has amply indicated that it is not possible to create or maintain anything like equitable pay conditions without developing and administering a positionclassification plan to support them." ${ }_{3}$ Many librarians do not have the necessary position-classification plans. A preventing factor has been the lack of personnel specialists in librarianship.

The development of an equitable salary schedule is readily attained when a posi(Continued on page 36I)

${ }^{3}$ Civil Service Assembly, op. cit., p. 62. 
Eastern Illinois State College Library in Charleston.

Paul von Khrum has been appointed acquisition librarian of the Chicago Undergraduate Division of the University of Illinois.

Darthula Wilcox, formerly branch librarian in the Montclair, N.J., Public Library, is now librarian of the Columbia University School of Library Service.

John Sheldon has been appointed recataloger at the Knox College Library. Formerly, he was assistant librarian at Westminster College, Fulton, Mo.

Alice E. Phelps, of the Cleveland Public Library, became head cataloger of the Oklahoma A. \& M. College on September 15.

Willard O. Youngs, formerly reference li- brarian at Stanford University, has become head of the general reference department, Seattle, Wash., Public Library.

Ruth M. Erlandson, chief reference librarian at the Brooklyn College Library, has been granted a King Gustav $\mathrm{V}$ fellowship by the American-Scandinavian Foundation for study in Sweden during the academic year 1948-49. She will do independent research at the University of Upsala on educational and informational services in Sweden.

Lucy E. Fay, associate professor emeritus of the School of Library Service, Columbia University, and formerly acting librarian of Temple University, was awarded the degree of Doctor of Letters at Russell Sage College on May 30.

\section{Retirement}

Willis H. Kerr, professor of bibliography and librarian at Claremont College, became librarian emeritus and bibliographical consultant on July 1. Mr. Kerr has played a prominent part in building up the libraries of the Associated Colleges, consisting of Pomona College, Scripps College, Claremont Men's College, and Claremont College. The collections of these libraries now total over
225,000 volumes. Mr. Kêrr has also been active in A.C.R.L.

Dr. David W. Davies, who has been librarian at Pomona College and associate librarian at Claremont College, succeeds $\mathrm{Mr}$. Kerr. Dr. Davies is librarian at Claremont and director of the joint library activities of the four colleges, as well as continuing as head of the Pomona College library.

\section{The Position-Classification Plan}

\section{(Continued from page 346)}

tion-classification plan exists. Pressure for special pay or pay increases on the part of certain individuals or groups confuses the salary policy of a library without a pay plan based on a position-classification plan. This tends to allow salaries to quickly approach their maximums. During periods of increasing cost of living, for example, high rate salary increases in the lower pay brackets result in a serious squeeze toward the maximum salaries.
Librarians have long been considered specialists in the systematic arrangement of materials. They know the value of system, although they have been slow to apply it to personnel management. The advantages of a classification plan of university library positions suggest that it is desirable for an efficient personnel policy. It needs only to be kept in mind that this is a classification of positions, and not of librarians holding those jobs. 